\title{
El actuar del Dr. Li Wenliang ante el brote del COVID-19 a la luz del principio de beneficencia
}

\author{
PABlo Ayala ENRIQUez \\ Tecnológico de Monterrey (México) \\ pabloayala@tec.mx \\ DANIEL LEMUS-DELGADO** \\ Tecnológico de Monterrey (México) \\ dlemus@tec.mx
}

\begin{abstract}
Resumen
Tomando como punto de partida las condiciones del contexto socio político donde se originó el brote epidémico del virus SARS-CoV-2, los autores analizan la influencia que tuvo el principio de beneficencia como una de las razones éticas que condujeron al oftalmólogo Li Wenliang a alertar a través de la red social Weibo, sobre el surgimiento de un brote epidémico distinto, por su agresividad, al del SARS. Se asume que dicho principio puede comprenderse a partir de un enfoque donde se conjugan referentes occidentales -la primera formulación del imperativo categórico kantiano y el legado hipocrático- y orientales -el principio del Ren o humanidad, derivado del pensamiento confuciano-. El artículo concluye señalando que en un mundo interrelacionado donde las prácticas médicas tienen fundamentos científicos universales, es posible tomar decisiones éticas médicas válidas para diferentes contextos culturales, siempre y cuando se continúe avanzando en el terreno de un diálogo inter-civilizatorio con perspectiva horizontal.
\end{abstract}

Palabras clave: COVID-19, principio de beneficencia, objeción de conciencia, imperativo categórico, Confucionismo.

\section{Dr. Li Wenliang, COVID-19 outbreak and the principle of beneficence}

\begin{abstract}
This article analyzes the influence of the principle of beneficence as one of the ethical reasons that led ophthalmologist Li Wenliang to alert, using the Weibo platform, about the emergence of an epidemic outbreak different from SARS. Accordingly, we discuss the socio-political context of the SARS-CoV-2 epidemic in China. We assume that the principle of beneficence might be understood from an approach combining Western references - the first formulation of the Kantian categorical imperative and the Hippocratic legacy - with Oriental ones - the Ren or bumanity, derived from Confucian thought. We conclude that in an interrelated world, with medical practices having universal scientific foundations, it is possible to validate medical ethical decisions from different cultural contexts, as long as progress continues in the field of an inter-civilizational dialogue with a horizontal perspective.
\end{abstract}

Key words: COVID-19, principle of Beneficence, conscientious objection, categorical imperative, Confucianism.

* Doctor en Ética y Democracia por la Universidad de Valencia, España. Actualmente es Decano Asociado de Formación Ética y Ciudadana en el Tecnológico de Monterrey. Entre sus publicaciones destacan: "From Moral awareness to academic integrity in Latin America" (2020).

** Doctor en Relaciones Internacionales y profesor investigador de la Escuela de Ciencias Sociales y Gobierno en el Tecnológico de Monterrey. Entre sus artículos recientes destaca "The Geopolitical Factor of Belt and Road Initiative in Latin America" (2020). 


\section{RINOCERONTES GRISES Y CISNES NEGROS}

En enero de 2019, Xi Jinping, presidente de China y Secretario General del Partido Comunista Chino (PCC), pronunció un discurso en la Escuela Central del Partido donde señaló que la seguridad y la estabilidad de China eran asechadas por amenazas, tanto internas como externas, de ahí que China debería estar preparada para enfrentar sucesos impredecibles en un entorno internacional complicado y sensible. Xi solicitó a los altos funcionarios del PCC mantenerse en alerta máxima con respecto a dos tipos de incidentes: los "cisnes negros" y los "rinocerontes grises". Estos últimos corresponden a riesgos conocidos que se ignoran en ese momento, mientras que los cisnes negros son sucesos desconocidos altamente imprevistos, por ello, había que mantener en alto la "guardia contra los cisnes negros y vigilar a los rinocerontes grises" (Lam, 2019: 6).

Un año después de aquellas palabras, la dirigencia del PCC se vio amenazada por la aparición de un cisne negro en la ciudad de Wuhan, epicentro de un nuevo tipo de coronavirus, denominado por la Organización Mundial de la Salud como SARS-CoV-2 (Organización Mundial de la Salud, 2020a), poniendo a prueba la capacidad y liderazgo de la élite burocrática china para enfrentar una emergencia sanitaria que confinó por varias semanas a más de cuarenta millones de residentes de la Provincia de Hubei, y a buena parte del resto del país (Graham-Harrison \& Kuo, 2020).

Aunque el gobierno chino había lidiado entre 2002 y 2003 con una crisis sanitaria derivada de otra enfermedad respiratoria, el SARS, la nueva enfermedad, también denominada Covid-19, representaba una amenaza aún mayor debido a la incertidumbre que había respecto a la velocidad de su propagación, las formas de contagio y tasa de letalidad (Szabo, 2020). Para complicar aún más las cosas, el brote se dio durante los días previos al año nuevo chino, de ahí que aeropuertos, estaciones de trenes y autobuses y la red de transporte de las ciudades, seguramente, experimentarían una inmensa presión ante la demanda de alrededor de 3 mil millones de viajes durante esta festividad (Bloomberg News, 2020). Paradójicamente, la alegría de tan esperada fecha se diluía ante la posibilidad de una propagación exponencial del virus.

A pesar de que el nuevo virus podría ser igual o peor que el SARS, las autoridades de la provincia de Hubei liberaron un rinoceronte gris al encubrir deliberadamente el brote, tal como señaló el presidente de China (Griffiths, 2020), situación que llegó a los oídos de muchos actores y, en particular, a los de algunos miembros de la comunidad médica. El médico oftalmólogo Li Wenliang, fue una de las primeras personas en sugerir que China se encontraba frente a una nueva enfermedad, por ello no dudó en 
enviar un mensaje de texto a un reducido grupo de colegas, con el propósito de alertarlos sobre algunos casos de pacientes que fueron internados en el Hospital Central de Wuhan, con el fin de que tomaran las medidas pertinentes (Gardner, 2020). La experiencia vivida en torno a la virulencia y efectos del SARS, no dejaban mucho margen de duda; el tiempo era un factor clave.

Si el olfato médico de Li le daba la razón, las autoridades sanitarias debían actuar lo más pronto posible para aislar a los pacientes, frenar la propagación del virus y evitar que este se convirtiera en una epidemia sin control. Por el contrario, si esta intuición clínica no era la correcta, lo dicho por él a través del mensaje enviado por la red social Weibo podría convertirse en un factor de desestabilización social, de ahí que la información continuaba siendo un aspecto clave para el control de la enfermedad.

$\mathrm{El}$ mensaje de Li que circulaba en las redes sociales chinas, tuvo un efecto que se tornó virulento y, en cierta forma, incontrolable (Ryan, 2020). Como parte del cuerpo médico de un hospital público, Li sabía de los riesgos que traía consigo compartir un mensaje en medio de estas circunstancias, de ahí que, pensamos, su comportamiento estuvo movido por un trasfondo ético que le condujo a desafiar la ordenanza impuesta en China, respecto al tipo y tono de los mensajes que pueden circular a través de las redes sociales (Yan, 2015).

Visto desde este ángulo, la objeción de conciencia podría ser una de las claves que nos permitiría comprender las motivaciones éticas de Li para haber actuado de esa manera, si esta se entiende como "la negación de una persona concreta o de un determinado grupo social a observar una conducta ordenada por la ley, alegando motivos de conciencia, presentándose como la oposición entre la ley y las convicciones personales de aquél que se niega a cumplirla" (Pacheco, 2020: 10).

Sin embargo, quien apela a la objeción de conciencia manifiesta la necesidad de defender la libertad religiosa o de conciencia ante la obligatoriedad de cumplir una determinada ley, de ahí que, en este caso, extrapolar dicho mecanismo a las razones que motivaron el actuar de Li, podría ser erróneo debido a que él no pretendía negar la atención médica a un paciente por motivos religiosos o morales, ni tampoco existen registros de su reticencia para acatar las normas relativas al uso de las redes en China.

Ahora bien, si la objeción de conciencia no fungió como el referente ético que motivó a Li a enviar un mensaje a sus colegas para prevenirles y evitarles un daño, ¿tuvo algún papel el principio de la beneficencia promovido por la Bioética? ¿Es posible recuperar dicho referente en la práctica médica occidental en el contexto oriental?

Con el propósito de conocer cuál fue el papel que jugó dicho principio en las decisiones del Dr. Li, el resto del artículo se encuentra organizado 
en cuatro secciones. La primera aborda cronológicamente el surgimiento del Covid-19 y la estrategia gubernamental aplicada a nivel local en la provincia de Hubei, y la nacional promovida por el PCC. La segunda sección analiza las reacciones gubernamental y pública ante la actuación del Dr. Li cuando sospechó de la presencia de un nuevo virus. La tercera sección, tomando como punto de partida el deber contenido en una buena voluntad que tiene por fin "evitar el daño", examina la influencia del principio de la beneficencia desde dos raíces distintas y, a la vez, interconectadas: la hipocrática y la confucionista. La cuarta sección se dedica a las conclusiones.

2. LA APARICIÓN DE LA PANDEMIA Y LA DOBLE RESPUESTA DEL GOBIERNO CHINO

El 31 de diciembre de 2019, la Comisión Municipal de Salud de Wuhan informó a la Organización Mundial de la Salud de un brote de veintisiete casos similares a la neumonía (Organización Mundial de la Salud, 2020b). En un primer momento, se afirmó que el origen de aquél se ubicó en el mercado de pescados y mariscos de Hua Nan, en la ciudad de Wuhan (Rosenbaum, 2020). Más adelante, el gobierno chino reconocería que el primer caso de un paciente con Covid-19, se presentó el 17 de noviembre y que, al menos, en 2019 sumaron 266 las personas infectadas con el nuevo coronavirus, mismas que se mantuvieron bajo vigilancia médica (Ma, 2020).

En tanto las autoridades de Wuhan terminaban de reconocer la presencia del virus, su primera "reacción táctica" fue negar que se atravesaba por una crisis sanitaria similar al brote del SARS del año 2002-2003, de ahí que censuraron cualquier información al respecto que pudiera circular más allá del minúsculo grupo de personas responsables de controlar el brote (Li, 2020). A pesar de sus intentos, no pudieron evitar que a punto de finalizar 2019, ocho personas vinculadas de distintas maneras al Hospital Central de Wuhan compartieran por la red social de Weibo algunas impresiones respecto a la manera en que varios pacientes mostraban un rápido deterioro y fallas graves en sus sistemas respiratorios.

El primero de enero de 2020, la policía de Wuhan afirmó que habían "tomado medidas legales" contra estas ocho personas que habían "difundido rumores" respecto a la enfermedad (Hong, 2020). Cinco días más tarde se confirmó que en Wuhan había pacientes con neumonía, cuando el origen de la enfermedad se encontraba en un virus distinto al de la influenza estacional, el SARS y el MERS (Aljazeera, 2020) y del que desconocían su morbilidad, velocidad de expansión y letalidad. 
El 11 de enero se anunció el primer fallecimiento por la nueva enfermedad y actualizó en 41 la cifra de personas contagiadas (Kantis, Kiernan $\&$ Bardi, 2020) ${ }^{1}$. Cinco días más tarde, las autoridades informaron el fallecimiento de un segundo paciente, y el 13 se reportó un caso en Tailandia que condujo a las autoridades chinas a reconocer la posibilidad de estar frente a un virus no solamente desconocido hasta ese momento, sino que el contagio se podía dar también entre las personas.

El domingo 18 de enero, las autoridades locales decidieron llevar a cabo su tradicional banquete para celebrar el año nuevo chino. Alrededor de diez mil familias se reunieron para compartir la mesa en una tradición que, además de regalarles un momento de alegría, sirvió para poner a hervir el caldo de cultivo del Covid-19 (Wei \& Deng, 2020), tal como reflejó el repunte registrado entre el 14 y el 20 de enero ${ }^{2}$.

El 20 de enero el Centro Chino para el Control y Prevención de Enfermedades, aceptó que el Covid-19 podía transmitirse de humano a humano $^{3}$. La importancia de tal descubrimiento radicó en que las autoridades lograron dimensionar la gravedad de la situación, en caso de que los brotes detectados llegaran a convertirse en pandemia. En el marco de dicho escenario, ese mismo día, el presidente chino Xi Jinping, dio instrucciones precisas a todos los niveles de los comités y gobiernos del partido, sobre la necesidad de priorizar la seguridad y salud de las personas, desplegar planes exhaustivos, tomar medidas efectivas para frenar la propagación del virus, divulgar información oportunamente y profundizar la cooperación internacional (Xinhua, 2020).

De esta manera, el gobierno emprendió una campaña para obtener una victoria en dos frentes. En el primero buscaba contener la expansión del Covid-19 y salvar la mayor cantidad de vidas posibles; por ello, de inmediato, se pusieron en marcha una serie de medidas para garantizar el aislamiento social y focalizar el brote en la provincia de Hubei. Desde el otro frente de batalla se intentaba evitar que se esparcieran el miedo, la

La cronología de los eventos de la difusión del coronavirus, al menos que se indique lo contrario, se basan en el documento autoría de Kantis, Kiernan \& Bardi (2020)

2 Es importante advertir que, durante las dos semanas posteriores al reconocimiento del nuevo virus, el Centro Nacional de Control de Enfermedades de China, prácticamente, no registró casos nuevos, aun y cuando los pacientes continuaban llegando a hospitales de Wuhan y el resto del país.

3 Si antes del 20 de enero, el gobierno hubiese aplicado las medidas de distanciamiento social requeridas, exigido el uso de mascarillas y limitado los desplazamientos, probablemente el número de contagios se hubiese reducido hasta en un $86 \%$ el número de contagios. (Lai, Ruktanonchai, Zhou, Prosper, Luo, Wesolowski, Santillana, Zhang, Du, Yu, \& Tatem, 2020). 
incertidumbre, la irritación y, muy especialmente, las críticas sobre el manejo de la crisis sanitaria que pusieran en entredicho la legitimidad del rol que, hasta ese momento, había tenido el Partido Comunista Chino. Tuvo que pasar más de un mes del brote de la enfermedad para que el presidente Xi Jinping realizara su primera visita a Wuhan, enviando con ello la señal de que los esfuerzos del gobierno central en el control del virus habían funcionado adecuadamente (Tian \& Lee, 2020).

El 22 de enero se anunció que al día siguiente se aplicaría una cuarentena total para la ciudad de Wuhan. Cuarenta y ocho horas más tarde, la medida se amplió a todas las ciudades de la provincia de Hubei, aislando por completo a una población de alrededor de cuarenta y cinco millones de personas (Jiang \& Ni, 2020).

3. LAS REACCIONES GUBERNAMENTAL Y PÚBLICA ANTE EL ACTUAR DEL DR. LI WENLIANG

En 2014, Li Wenliang asumió el puesto de oftalmólogo en el Hospital Central de Wuhan, nosocomio considerado como el epicentro del brote de Covid-19 (Green, 2020), y desde el que, a través de Weibo, el Dr. Li advirtió la llegada de siete pacientes con signos similares a los del SARS, tan solo unos días antes de que las autoridades chinas admitieran el brote de un nuevo coronavirus, y al que la Oficina de Seguridad Pública de Wuhan había acusado de "difundir rumores falsos" que perturbaban el orden público, obligándole a firmar un documento policial donde admitía que había "perturbado gravemente el orden social" y había violado la ley (BBC, 2020).

Una semana después de su encuentro con las autoridades, este médico de 33 años desarrolló fiebre, y murió el siete de febrero tras haber sido diagnosticado con Covid-19 (BBC, 2020). Pocos días antes de su fallecimiento, en una entrevista donde se le preguntaba sobre cómo se sentía tras la presión de la policía para declararse culpable, señaló: "Sentí que me estaban haciendo daño, pero tenía que aceptarlo. Obviamente babía estado actuando por buena voluntad. Me sentí muy triste al ver tanta gente perdiendo a sus seres queridos" (New York Times, 2020).

La trama de los últimos días de vida y el desenlace fatal del Dr. Li Wenliang, desataron en la opinión pública nacional y extranjera, una mezcla de asombro, indignación y rabia (Radio France International, 2020). Los censores gubernamentales se vieron abrumados por la ola de publicaciones críticas, incluidas algunas que culpaban directamente al gobierno de la muerte de Li (Shih, 2020). La irritación aumentó cuando se hizo evidente que aquel primer mensaje de $\mathrm{Li}$, más que un "comentario falso", fue uno 
de los primeros anuncios que alertaba sobre la peligrosidad de la enfermedad. En consecuencia, el nivel inusual de enojo público contra el Partido Comunista llevó a su poderoso cuerpo interno anticorrupción, la instancia más alta del país en esta materia, a realizar una investigación exhaustiva en Wuhan sobre los problemas ventilados en torno al caso del Doctor Li Wenliang (Davidson, 2020). El 20 de marzo el médico fue exonerado oficialmente por los resultados de la investigación realizada en torno a su muerte (Davidson, 2020).

\section{UNA APROXIMACIÓN ÉTICA A LAS RAZONES QUE ESTUVIERON DETRÁS DEL ACTUAR DEL DR. LI WENLIANG}

Si el Dr. Li Wenliang no se ocultó tras el anonimato del que se vale un whistleblower, ni se detuvo ante las posibles consecuencias de usar Weibo, ¿qué razones le condujeron a advertir a sus colegas sobre el brote epidémico que detectó con la llegada de algunos pacientes que arribaron al Hospital Central de Wuhan?

De entrada, es posible deducir tres tipos de razones: una personal, una médica y una moral. Es probable que los casos vistos por Li en el hospital, le hayan permitido inferir que la situación podría salirse de las manos, por ello, como amigo y colega, pensó que debía prevenir a sus compañeros sobre las posibilidades de contraer el virus si no tomaban las medidas pertinentes. La experiencia adquirida durante el brote epidémico del SARS, le permitió atar los cabos clínicos para concluir que era necesario actuar con mucha celeridad. La tercera razón, pensamos, estuvo asociada a la buena voluntad declarada por Li, y que podríamos entender como esa facultad práctica de la razón "que establece un mínimo normativo que un ser racional debe cumplir, si es que quiere seguir siendo tenido como tal" (Cortina, 1988: 182). Sobre el modo que operó este peculiar tribunal de la conciencia, hablaremos con más detenimiento en el siguiente apartado.

4.1. Del tribunal de la conciencia kantiano al principio de la beneficencia de la Bioética

El eco del dictado de la razón pura práctica ${ }^{4}$ que como médico condujo a $\mathrm{Li}$ a actuar de esa manera, pensamos, refleja con bastante claridad

$4 \quad$ La Metafísica de las costumbres, obra clave en el pensamiento ético kantiano, inicia "previniendo contra toda pretensión de extraer el deber de la experiencia y contra toda pretensión de extraerlo de la naturaleza humana. Por ello es menester 'perseguir' y exponer claramente la facultad práctica de la razón, desde sus reglas universales de determinación, hasta allí donde surge el concepto del deber. El deber tiene su origen en la voluntad pura, y con ello hemos llegado al núcleo de la filosofía práctica" (Cortina, 
la primera formulación del imperativo categórico: "Obra sólo según aquella máxima por la cual puedas querer que al mismo tiempo se convierta en ley universal" (Kant, 2012: 126). La actuación de Li, como veremos, se dio de un modo incondicionado, tal como obra la buena voluntad en el actuar moral kantiano, y donde el punto de partida del actuar ético no reside en el bien que determinan nuestros puros deseos, sino "en el deber que reconocemos interiormente como criaturas racionales; porque el deber no es deducible del bien, sino que el bien propio y específico de la moral no consiste en otra cosa que el cumplimiento del deber" (Cortina y Navarro, 2001: 71).

Con relación al punto de partida del deber moral, Kant es muy claro al respecto: hay que actuar por el deber y no conforme al deber; actuar de esta última forma no podría considerarse un acto moral en sí, sino uno egoísta. Quien actúa conforme al deber respeta la norma porque le conviene, porque obtiene algún beneficio de ello, pero no porque considere que sea bueno respetarla, de ahí que la primera formulación del imperativo categórico pretenda que las normas sean observadas por sí mismas, no en función de lo que se obtenga a través de su cumplimiento ${ }^{5}$.

Así pues, quien actúa a partir del mandato de su conciencia moral, dirá Kant, se sentirá "observado, amenazado y sometido a respeto -respeto unido al temor- por un juez interior. Tal autoridad, que vela en él por las leyes no es algo producido arbitrariamente por él mismo, sino inherente a su ser. Cuando pretende huir de ella, le sigue como su sombra. Puede, sin duda, aturdirse y adormecerse con placeres y distracciones, más no puede evitar volver en sí y despertar de cuando en cuando tan pronto como percibe su terrible voz. Puede incluso, en su extrema depravación, llegar a no prestarle atención, pero lo que no puede en ningún caso es dejar de oírla” (Kant, 2012: 303).

Siguiendo este paradigma de racionalidad práctica, es posible afirmar que el mandato de este "juez interior" que obró en el tribunal de la conciencia del Dr. Li, fue el propulsor moral que le impulsó a utilizar las redes

1988: 150). En este sentido, damos por sentado que la buena voluntad manifiesta en la acción del Dr. Li, como veremos, obra a partir de una máxima que puede convertirse en ley universal.

5 En la Fundamentación de la metafísica de las costumbres, Kant busca demostrar "que hay un significado de 'bueno' que tiene que ser reconocido por todos (sobre la base de su racionalidad). Si suavizamos dicha pretensión de tal modo que permita mostrar, dado el caso, que hay un sentido de 'bueno' y no otro que no debe ser reconocido por todos pero que puede serlo, se habría dado un paso esencial más allá de las justificaciones relativas. Esto se lograría si se mostrara, primero, que hay un sentido de 'bueno' que sugiere un reconocimiento universal que es plausible y, segundo, que todas las propuestas conocidas no son (o son menos plausibles)" (Tugendhat, 2001: 77). 
sociales para advertir a sus colegas del peligro que se avecinaba, sobreponiéndose a sus inclinaciones y temores derivados de lo que consideró su deber moral. Pensamos que esta forma de actuación proyecta la buena voluntad del Dr. Li, misma que, en este caso, extiende su influjo hasta el principio de beneficencia promovido por la Bioética ${ }^{6}$.

La manera en que opera el principio de la beneficencia en el terreno de la práctica médica, podría sintetizarse en los siguientes términos: el individuo $X$ tiene la obligación de hacer el bien al individuo $Y$, cuando $Y$ está amenazado de padecer una pérdida o daño importante. En ese sentido, la acción de $\mathrm{X}$ se vuelve necesaria para evitar un daño o pérdida importante en $\mathrm{Y}$, sobre todo, si esta acción no implica un daño significativo para $\mathrm{X}$, de ahí que los beneficios que recibirá $\mathrm{Y}$ superen ampliamente los daños que pudiera sufrir X (Gafo, 2012).

Si extrapolamos esta lógica de aplicación al caso del Dr. Li Wenliang, este sería $\mathrm{X}$, y sus amigos-colegas del grupo de Weibo serían Y. Al desconocer la presencia del virus detectado por X, Y estaba bajo una clara amenaza derivada del contagio, de ahí que la acción de $\mathrm{X}$ se volvía necesaria para evitar el daño de Y. Siendo todos médicos, la mera advertencia contenida en el mensaje, seguramente, evitaría el daño, porque todos sabían las vías de contagio y sus efectos. En principio X no debía haberse sentido demasiado preocupado por un mensaje que, más que un rumor, era una advertencia realizada por un médico que actuaba movido por el principio hipocrático-confuciano de generar el bien evitando un daño. En ese sentido, los beneficios para $\mathrm{Y}$ eran mayores que el mal que pudiera sufrir $\mathrm{X}$. Por tanto, estamos ante una "acción virtuosa, que supera el campo de la obligación" (Gafo, 2012), en este caso, el no enviar mensajes por Weibo que puedan confundirse con rumores o, dicho en términos confucianos, estamos ante una situación donde primó la regla de la benevolencia sobre la regla de la ley (Zhaojiang, 1995).

Visto de esta forma, sugerimos que el actuar benevolente del Dr. Li, comparte sus fundamentos con la filosofía moderna europea y, muy particularmente, con el pensamiento humanista de Confucio, tal como dará cuenta el siguiente apartado.

\footnotetext{
6 Aunque la noción de Bioética tiene vínculos con una historia que se remonta al tiempo de los neopitagóricos griegos, fue hasta 1971 que el término vio la luz en el libro Bioethics: a Bridge to the Future. Esta obra, publicada por el cancerólogo Van Rensselaer, este concepto se define como “...el estudio sistemático de la conducta humana en el área de las ciencias humanas y la atención sanitaria, en cuanto se examina esta conducta a la luz de valores y principios morales". (Gafo, 2009: 11).
} 
4.2. El principio de beneficencia en la práctica médica china

Es un hecho que, al día de hoy, la práctica médica se fundamenta en el Corpus Hippocraticum legado por la civilización occidental. Sin embargo, algunas tradiciones culturales también poseen documentos similares que embonan con el contenido del juramento de Hipócrates ${ }^{7}$. Una revisión detenida de cada uno de ellos permite descubrir cuatro puntos donde todos coinciden: "En primer lugar, el primum non nocere, 'ante todo no hacer daño'; la afirmación de la santidad de la vida humana; la necesidad de que el médico alivie el sufrimiento y, finalmente, la santidad de la relación entre el médico y el enfermo..." (Gafo, 2012: 12).

Este telón de fondo ha servido a la práctica e investigación médica china actual, para configurar un referente ético que integra principios y pautas derivadas del pensamiento hipocrático, contenido en la bioética occidental, con algunas ideas filosóficas legadas del confucianismo, entre las que destacan: "Las personas son aquellas que se aman las unas a las otras", "La persona es quien respeta a los otros", "Los principios de la decencia van en paralelo con la naturaleza del taoísmo" o "La medicina es fundamentalmente caridad" (Li, 2008).

A la luz de este legado podemos decir que la práctica médica china, el confucianismo y la bioética occidental comparten algunas aspiraciones y metas asociadas al reconocimiento y defensa del valor de la vida humana, el alivio del sufrimiento, el cuidado del paciente, la práctica íntegra y honesta, el trato justo y, entre otras más, el respeto de las reglas éticas $(\mathrm{Li}$, 2008). La suma de estas pautas de actuación, sistematizada a través de "una estructura de principios morales, con la bondad como centro nuclear", el respeto, la empatía y la dignidad humana, vendrán, pues, a convertirse en el punto de referencia ético para la práctica médica china (Li, 2008).

Ahora bien, si este referente ético lo damos por válido, podemos pensar que estamos más cerca de comprender las motivaciones que llevaron al Dr. Li Wenliang a actuar del modo que lo hizo. ¿Era posible actuar de otra manera, cuando las enseñanzas de Confucio y los deberes asociados a la ética médica dictan que es una obligación hacer el bien y evitar el daño? ¿Era posible actuar de otro modo cuando el principio de beneficiar al otro también resulta ser un imperativo moral en la tradición civilizatoria y práctica médica china?

Habría que citar aquí “el llamado 'Juramento de Iniciación', Caraka Samhita, del siglo I a.C., procedente de India; el Juramento de Asaph, dentro del mundo judío, probablemente del siglo III-IV d.C. y el Consejo de un Médico, del siglo X d.C., procedente de la medicina árabe. En la cultura china se citan Los cinco mandamientos y las diez exigencias, de Chen Shih-kung, médico chino de comienzos del siglo XVII, que constituye la mejor síntesis médica de esta cultura" (Gafo, 2012). 


\subsection{Una aproximación confucionista al principio de beneficencia}

El origen cultural del principio de beneficencia en la civilización china, tiene su raíz en el pensamiento de Confucio. Las enseñanzas de Confucio, tal como han sido recogidas en las Analectas, colocan al ser humano en el centro de su pensamiento, de ahí que sus preocupaciones, al ser propiamente humanas, le lleven a proponer un modelo superior de comportamiento en el aquí y en el ahora, dirigido al beneficio de toda la humanidad ${ }^{8}$. Para ello, Confucio propone una serie de virtudes que orientan el actuar de cualquier persona, sin excepción alguna.

La concepción axiológica confuciana estructurada en dos niveles. En el primero se encuentran el ren (仁) -humanidad o benevolencia- enmarcado en los conceptos dé (德) -virtud- y dào (道) -camino-. Estos conceptos, por su significado, pretenden ser universales, en el sentido que son aplicables en cualquier situación y válidos para todos los seres humanos. Los tres elementos son considerados holísticamente por lo que no pueden ni separarse ni jerarquizarse. El ren, el dé y el dào son mutuamente contenidos e intercambiables. En un segundo nivel, se encuentran otras cualidades como z̧ōng (忠) (lealtad), xiào (孝) (piedad filial), gōng (恭) (respeto), xing (性) (veracidad) y yǒng (勇) (valentía). El hecho de que sean consideradas cualidades de segundo nivel no significa que resulten menos importantes. En todo caso, esta clasificación se deriva del hecho de que son tratadas como aplicaciones y extensiones del primer nivel (Yao, 2012). Por lo tanto, es posible entender que el ren es la virtud que da sentido y significado a las demás y a la cual deben aspirar las personas, especialmente el funcionario ideal, el junzi (君子), una persona ejemplar, un caballero, una persona de mente superior, un noble ${ }^{9}$. Si partimos de esta concepción, el médico ideal, debería guiar su práctica médica por el ren.

En efecto, la visión humanística de la vida tiene su máxima expresión en el concepto de ren. Este es el corazón del confucianismo (Wang, 2012). Dicho concepto ha sido traducido como benevolencia, bondad, virtud o

\footnotetext{
$8 \mathrm{Al}$ respecto las Analectas dejan este testimonio: "El Maestro nunca habló de milagros, violencia, desórdenes ni espíritus” (Confucio, 1997: 21). Además, Confucio planteó con claridad un orden ético para el presente: Zilu inquirió: «¿Puedo preguntarte sobre la muerte? El Maestro respondió: «Todavía no conoces la vida, ¿cómo podrías conocer la muerte?»" (Confucio, 1997: 11-12).

9 El concepto de junzi $i$ hacía referencia a una categoría hereditaria, pero con Confucio se transformó en una categoría ética, la cual se alcanza por medio del crecimiento interior (Cheng, 2011) De esta manera, Confucio transforma la idea de junzi de aquella persona que pertenecía a una elite social a un nuevo individuo que pertenece a una elite moral (Leys, 1998).
} 
humanidad (Leys, 1998). Etimológicamente, esta palabra es escrita con el radical "humano" y el complemento "dos" (仁). Visto de esta manera, podría ser interpretado como ir "más allá" de sí mismo para entablar una relación con los demás (Ching, 1993). Aquella persona que lleva a la práctica el ren es un "hombre bueno", un "hombre virtuoso", un "hombre plenamente humano" (Leys, 1998). En este sentido, podríamos afirmar, una persona que aspira al ren se mueve por el principio de la beneficencia, porque sale de sí mismo con la intención de encontrarse con el otro para generar un bien.

La concepción del ren es la perfección de lo que significa ser humano. Originalmente, el concepto hacía referencia a la actitud de generosidad de un caballero hacia alguno de sus subalternos, como una expresión de magnanimidad, vinculada al origen social de quien la practicaba; pero, en las enseñanzas de Confucio, esta se transformó en una virtud universal, lo cual completa -hace perfecto-, al ser humano (Ching, 1993).

Entre las manifestaciones de una persona distinguida por alcanzar el ren se encuentra ser una persona digna de confianza (Confucio, 1997: 17,6). Esta confianza, evidentemente, es un elemento fundamental que debe estar presente en la práctica médica. En el ideal de Confucio, toda persona que tiene claro que la humanidad es construida, está dispuesta a dar la vida antes de renunciar a ella: "El Maestro dijo: «Un hombre recto, un hombre que practica la humanidad, no busca la vida a expensas de su humanidad; por el contrario, habrá ocasiones en que dará su vida para realizar su humanidad»" (Confucio, 1997: 15,9). Por lo tanto, es posible afirmar que el ren es un destino, una meta.

Desde esta perspectiva, ninguna persona nace plenamente humana. La humanidad se obtiene con el comportamiento diario hacia uno mismo y se concretiza en el trato hacia los demás. La esencia de la humanidad consiste en el amor a los otros ${ }^{10}$. Así, el amor es entendido como una forma de solidaridad empática con los demás, buscando hacer el bien sin esperar recompensa alguna.

El camino para alcanzar el ren es la educación. En las Analectas está escrito: "El Maestro dijo: «Un caballero no es una vasija»" (Confucio, 1997: 2,12). Si cualquier persona puede llegar a ser un caballero por su

10 Cuando un discípulo le preguntó a Confucio que es la humanidad él contestó «Amar a todos»" (Confucio, 1997: 12,22). El amar a todos significa en el colocarse en el lugar del otro para relacionarse con él. Cuando Zigong preguntó: «¿Hay alguna sola palabra que pueda guiarnos toda nuestra vida?» El Maestro respondió: «¿No sería la reciprocidad? Lo que no desees que te hagan a ti, no se lo hagas a los demás»" (Confucio, 1997: 15,2324). 
educación, entonces la capacidad de un ser humano no tiene un límite específico; un ser humano vale no por su utilidad, que es limitada, sino por su capacidad, que es ilimitada ${ }^{11}$. Desde esta perspectiva, en el campo de la medicina como en cualquier otro aspecto de la vida, lo importante no es la información especializada ni la capacidad técnica de las personas, sino el desarrollo de la humanidad misma. La educación no está relacionada con tener, sino con $\operatorname{ser}^{12}$. Por lo tanto, el buen médico no es aquel que hace un diagnóstico técnicamente perfecto, sino aquel que brinda un trato humano hacia sus pacientes y colegas, basado en la reciprocidad y la confianza.

El punto fundamental de la conceptualización de ren en la propuesta confuciana es que se convierte en un ideal humano que permite sintetizar las dinámicas tradicionalmente opuestas entre las aspiraciones individuales y las demandas colectivas. Si bien es cierto, la lectura del pensamiento confuciano durante siglos privilegió el aspecto colectivo de las relaciones personales encerrándolos en una serie de ritos, prácticas y costumbres sobre el deber ser, justificando un orden social jerárquico que imponía la sumisión como forma de control político y social desde una visión patriarcal de la sociedad, en los orígenes del pensamiento confuciano podemos ver con claridad la manera en que se destaca la libertad de decisión para desarrollar el ren. La materialización exterior del ren, a partir de las demás virtudes, solo es posible después de una decisión individual, personal, íntima. Así, por más que influya una presión social fuerte, la decisión de actuar en beneficio de otros a pesar de los riesgos que implica, como sucedió en el caso del Dr. Li, responde originalmente a un "deber ser", un mandato que la persona se da a sí misma.

Sin embargo, esto no significa que la realización del ren se logre exclusivamente en la individualidad. Su práctica consiste en la consideración de los otros (Fung, 1997). Es a partir de la convivencia con los otros, guiada por una serie de virtudes, como se puede conseguir la humanidad plena. El junzi tiene una perspectiva más amplia de las relaciones recíprocas que debían establecerse en sociedad, más allá de la solidaridad familiar (Confucio, 1997: 12,5). Un médico, embebido en una tradición confucionista, como lo refleja el caso del D. Li, toma como punto de partida la reciprocidad benevolente para asegurar la humanidad de sus decisiones.

11 De esta manera, Confucio plantea una especie de igualdad natural entre todos los hombres en términos de su capacidad para aprender; aunque existen diferencias entre las personas, estas provienen de cómo emplean sus capacidades y cuál es la voluntad de cada uno para poner en práctica lo aprendido (Cheng, 2011).

12 Tradicionalmente se concibió estudiar los clásicos no tenía como propósito la especulación filosófica, sino que el conocimiento aprendido debía ser vivido (Fung, 1997). 


\section{CONCLUSIONES}

El proceder benevolente del Dr. Li Wenliang refleja con bastante claridad la posibilidad de materializar el mandato del deber que vertebra el conjunto pretensiones morales contenidas en la Fundamentación de la metafisica de las costumbres, porque, como en ella Kant dice, "no es posible pensar nada dentro del mundo, ni fuera del mismo, que pueda ser tenido por bueno sin restricción alguna, salvo una buena voluntad" (Kant, 2012: 77). Quien actúa de esta manera, actúa por deber, un deber que busca la universalidad de una acción moral que reconoce "la igualdad y la igualdad sólo puede alumbrar el deber de respetarla" (Armengol, 2000: 75). Como se ha analizado en este artículo, para Li el cumplimiento del deber vino de la mano de un concepto de bien presente tanto en la ética médica occidental como oriental.

En ese sentido, sugerimos que ante las enfermedades globales a las que se enfrentan y atienden los médicos de todo el mundo, es posible actuar a partir de referentes éticos que superen los particularismos locales, apoyándose en principios éticos con alcance universal. Sin embargo, para que realmente dichos principios aspiren a una verdadera universalidad, resulta necesario que estos recuperen tradiciones éticas no occidentales, tal como nosotros hemos tratado de hacer. En eso reside la clave de la universalidad. La tarea, por tanto, es redescubrir otras aproximaciones de saberes y valores provenientes de contextos culturales diferentes, aparentemente irreconciliables, con el fin de renovar la ética de la práctica médica, a partir de sus puntos de encuentro y conexión, propiciando con ello una auténtica práctica ética médica universal. Como vimos, un ejemplo claro se encuentra en el pensamiento de Confucio respecto al ren, o humanidad, y su relación con el principio de beneficencia promovido por la Bioética occidental.

Pensamos que si logramos poner el principio de la beneficencia en un diálogo con perspectiva horizontal donde se conjunten los referentes de la civilización occidental y oriental, podremos dar pasos más firmes en la universalización de ciertas pautas éticas médicas, tal como lo reflejó el actuar benevolente del Dr. Li.

Más allá de los riesgos políticos derivados de difundir información que la autoridad podría clasificar, no solamente como falsa, sino como sediciosa, el Dr. Li asumió la decisión de alertar la situación que observaba en el hospital porque era una forma de relacionarse humanamente con sus amigos y compañeros desde la perspectiva del ren.

Así pues, si se reconoce que otras tradiciones no occidentales también cuentan con formas de apreciar la vida y valorar las prácticas médicas 
desde una visión humanista basada en principios que, desde nuestra experiencia occidental, podemos clasificar como principios bioéticos, dicha consideración podría abrir nuevos caminos para que la Bioética deje de ser universalista -impuesta desde un marco paradigmático exclusivo de una civilización-, para convertirse verdaderamente en universal, al reconocer marcos valorales que surgen en tradiciones no occidentales, pero coincidentes en la búsqueda del beneficio de la persona como persona en sí. De este afán, entendido como un deber universal, el Dr. Li podría ser buen ejemplo.

\section{REFERENCIAS}

Aljazeera (2020). Timeline: How the new coronavirus spread. Aljazeera. Disponible en: https://www.aljazeera.com/news/2020/01/timeline-china-coronavirus-spread-200126061554884.html

Armengol, R. (2000). Felicidady dolor: una Mirada ética. Madrid: Ariel.

BBC (2020). Li Wenliang: Coronavirus death of Wuhan doctor sparks anger. $B B C$. Disponible en: https://www.bbc.com/news/world-asia-china51409801

Bloomberg News (2020). China Will Rack Up Three Billion Trips During World's Biggest Human Migration. Bloomberg News. Disponible en: https://www.bloomberg.com/news/articles/2020-01-20/china-readiesfor-world-s-biggest-human-migration-quicktake

Cheng, A. (2011). Virtue and Politics: some conceptions of sovereignty in Ancient China. Journal of Chinese Philosophy, (38), 113-145.

Ching, J. (1993). Chinese Religions. Nueva York: Orbis Books.

Confucio (1997). Analectas, Madrid: Editorial Kairos.

Cortina, A. (1988). Dignidad y no precio. Más allá del economicismo. En E. Guisán (Ed.), Esplendor y miseria de la ética kantiana. (pp. 140-166). Madrid: Anthopos.

Cortina, A., \& Navarro, E. (2001). Ética. Madrid: Akal.

Davidson, H. (20 de marzo de 2020). Chinese inquiry exonerates coronavirus whistleblower doctor. The Guardian. Disponible en: https://www.theguardian.com/world/2020/mar/20/chinese-inquiry-exonerates-coronaviruswhistleblower-doctor-li-wenliang

Fung, Y. (1997). A short history of Chinese Philosophy. New York: Free Press.

Gafo, J. (2009). 10 palabras clave en Bioética. Madrid: Editorial Verbo Divino.

Gardner, P. (2020). China's coronavirus cover-up: how censorship and propaganda obstructed the truth. The Conversation. Disponible en: https://theconversation.com/chinas-coronavirus-cover-up-how-censorship-and-propaganda-obstructed-the-truth-133095 
Graham-Harrison, E., \& Kuo, L. (2020). China's coronavirus lockdown strategy: brutal but effective. The Guardian. Disponible en: https://www.theguardian.com/world/2020/mar/19/chinas-coronavirus-lockdown-strategybrutal-but-effective

Green, A. (2020). Li Wenliang. The Lancet, 395(10225), 682. https://doi.org/10.1016/S0140-6736(20)30382-2.

Griffiths, J. (2020). ¿Sabía Xi Jinping sobre el brote de coronavirus antes de lo que se ha dicho? CNN. Disponible en: https://cnnespanol.cnn.com/2020/02/17/sabia-xi-jinping-sobre-el-brote-de-coronavirusantes-de-lo-que-se-ha-dicho/

Hong, B. (2020). China Arrested Doctors Who Warned About Coronavirus Outbreak. Now Death Toll's Rising, Stocks Are Plunging. The Daily Beast. Disponible en: https://www.thedailybeast.com/china-arrested-doctors-whowarned-about-coronavirus-outbreak-now-death-tolls-rising-stocks-areplunging

Jiang, W., \& Ni, A. (2020). Why the coronavirus has become a major test for the leadership of $\mathrm{Xi}$ Jinping and the Communist Party. The Conversation. Disponible en: https://theconversation.com/why-the-coronavirus-has-become-a-major-test-for-the-leadership-of-xi-jinping-and-the-communistparty-130788

Kant, I. (2008). La metafísica de las costumbres. Madrid: Tecnos.

Kant, I. (2012). Fundamentación para una metafísica de las costumbres. Madrid: Alianza. Kantis, C., Kiernan, S., \& Bardi, J.S. (2020). UPDATED: Timeline of the Coronavirus. Think Global Health. Disponible en: https://www.thinkglobalhealth.org/article/updated-timeline-coronavirus

Lam, W. (2019). Xi Jinping Warns Against the "Black Swans" and "Gray Rhinos" of a Possible Color Revolution. The Jamestown Foundation. Disponible en: https://jamestown.org/wp-content/uploads/2019/03/Read-the-03-052019-CB-Issue-in-PDF1.pdf?x88160

Leys, S. (1998). Confucio: Analectas, versión y notas. Madrid: EDAF.

Lai, S., Ruktanonchai, N., Zhou, L., Prosper, O., Luo, W. Floyd, J., Wesolowski, A., Santillana, M., Zhang, C. Du, X., Yu, H., \& Tatem, A. (2020). Effect of non-pharmaceutical interventions for containing the COVID-19 outbreak in China. MedRxiv, 1-29. https://doi.org/10.1101/2020.03.03.20029843

Li. E-C. (2008). Bioethics in China. Bioethics, 22(8), 448-454.

Li, Y. (2020). China Silences Critics Over Deadly Virus Outbreak. The New York Times. Disponible en: https://www.nytimes.com/2020/01/22/health/virus-corona.html

Ma, J. (2020). Coronavirus: China's first confirmed Covid-19 case traced back to November 17. South China Morning Post. Disponible en: https://www.scmp.com/news/china/society/article/3074991/coronavirus-chinas-first-confirmed-covid-19-case-traced-back

New York Times (2020). He Warned of Coronavirus. Here's What He Told Us Before He Died. 2020. The New York Times. Disponible en: https:/ / www.nytimes.com/2020/02/07/world/asia/Li-Wenliang-china-coronavirus.html 
Organización Mundial de la Salud (2020a). Los nombres de la enfermedad por coronavirus (COVID-19) y del virus que la causa. Organización Mundial de la Salud. Disponible en: https://www.who.int/es/emergencies/diseases/novel-coronavirus-2019/technical-guidance/naming-the-coronavirus-disease(covid-2019)-and-the-virus-that-causes-it

Organización Mundial de la Salud (2020b). Nuevo coronavirus - China. Organización Mundial de la Salud. Disponible en: https:/ /www.who.int/csr/don/12january-2020-novel-coronavirus-china/es/

Pacheco, A. (2020). Ley y conciencia. Disponible en: https://biblio.juridicas.unam.mx/bjv/detalle-libro/156-cuadernos-del-instituto-de-investigaciones-juridicas-objecion-de-conciencia

Radio Francia Internacional (2020) China: la muerte del doctor que alertó sobre el coronavirus desata ola de indignación. 2020. Radio Francia Internacional. Disponible en: http://www.rfi.fr/es/salud/20200207-china-la-muerte-deldoctor-que-alert $\% \mathrm{C} 3 \% \mathrm{~B} 3$-sobre-el-coronavirus-desata-ola-de-indignaci $\% \mathrm{C} 3 \% \mathrm{~B} 3 \mathrm{n}$

Rosenbaum, L. (2020). Everything You Need to Know About the Current Coronavirus COVID-19 Outbreak. Forbes. Disponible en: https://www.forbes.com/sites/leahrosenbaum/2020/01/23/everything-you-need-toknow-about-the-wuhan-coronavirus-outbreak/\#1affbb046fce

Ryan, M. (2020). China's coronavirus blame game. East Asia Forum. Disponible en: https://www.eastasiaforum.org/2020/03/02/chinas-coronavirusblame-game/

Shih, G. (2020). As Wuhan's lockdown ends, residents leave messages for the dead doctor who sounded the alarm on coronavirus. The Washington Post. Disponible en: https://www.washingtonpost.com/world/asia_pacific/aswuhans-lockdown-ends-residents-leave-messages-for-the-dead-doctorwho-sounded-the-alarm-on-coronavirus/2020/04/08/82f1c602-799911ea-a311-adb1344719a9_story.html

Szabo, L. (2020). Facts Vs. Fears: Five Things to Help Weigh Your Coronavirus Risk. Kaiser Health News. Disponible en: https://khn.org/news/facts-vsfears-five-things-to-help-weigh-your-coronavirus-risk/

Tian, W.L., \& Lee, S.E. (2020). Xi visits Wuhan, signaling tide turning in China's coronavirus battle. Reuters. Disponible en: https://www.reuters.com/article/us-health-coronavirus-china/xi-visits-wuhan-signaling-tide-turning-inchinas-coronavirus-battle-idUSKBN20X01F

Tu, W. (1998). Confucius and Confucianism. En W.H. Slote and G.A. Devos (Eds.), Confucianism and the Family (pp. 3-36). Nueva York: SUNY Press.

Tugendhat, E. (2001). Lecciones de Ética. Barcelona: Gedisa.

Wang, H. (2012). Ren and Gantong: Openness of Heart and Root of Confucianism. Philosophy East \& West, 62(4), 463-504.

Wei, L., \& Deng. C. (24 de enero de 2020) China’s Coronavirus Response Is Questioned: 'Everyone Was Blindly Optimistic'. The Wall Street Journal. Disponible en: https://www.wsj.com/articles/china-contends-with-questionsover-response-to-viral-outbreak-11579825832 
Xinhua (2020). China publishes timeline on COVID-19 information sharing, int'l cooperation. Xinbua News. Disponible en: http://www.xinhuanet.com/english/2020-04/06/c_138951662.htm

Yan, M.N. (2015). The Impact of New Media on Freedom of Expression in China and Regulatory Responses. En P. Molnar (ed.), Free Speech and Censorship Around the Globe (pp. 381-408). Nueva York: CEU Press.

Yao, X. (2012). Introduction: Conceptualizing virtues in the Analects of Confucius. Journal of Chines Philosophy, 39(1), 3-7.

Zhaojiang, G. (1995). Chinese Confucian culture and the medical ethical tradition. Journal of Medical Ethics, 21(4), 239-246. 